\section{Review: limited evidence on regular breast examination does not support its effectiveness for reducing breast cancer deaths}

\author{
Kösters JP, Gøtzsche PC. Regular self-examination or clinical examination for early detection of breast cancer. Cochrane \\ Database Syst Rev 2003;(2):CD003373 (latest version 1 Feb 2003).

\section{QUESTION: Does screening for breast cancer by regular self examination or clinical examination (or both) reduce the incidence of breast cancer and death?}

Source of funding: no external funding.

A modified version of this abstract appears in Evidence-Based Nursing.

For correspondence: Dr J P Kösters, Nordic Cochrane Centre, Copenhagen, Denmark. mbx59852@cochrane.dk

\section{Data sources}

Studies were identified by searching Medline and the Cochrane Library (October 2002), reference lists, and the specialised register of the Cochrane Breast Cancer Group.

\section{Study selection}

Randomised controlled trials were included if they evaluated regular clinical or self breast examination in women with no diagnosis of breast cancer.

\section{Data extraction}

Data were extracted on patient characteristics, type of breast self examination, and outcomes (mortality from breast cancer, total mortality, cancers identified, and biopsies with benign results).

\section{Main results}

2 studies (388 535 women) that compared self breast examination with no examination were included. 1 study from St Petersburg, Russia followed 122471 women (40-64 y) for 10-15 years. 1 study from Shanghai, China followed 266064 women (30-66 y) for 10 years. Results were pooled using the fixed effects model. Breast cancer mortality did not differ between groups in the 2 studies (292/190691 for self breast examination $v$ 295/ 197844 for control) (table). The Shanghai study reported lower total mortality for the screening group than for the control group (relative risk reduction $10 \%$, 95\% CI 7 to 13). Heterogeneity existed between the studies for the number of cancers identified. The Russian study showed that more cancers were identified in the screening group than in the control group (relative risk [RR] 1.24, CI 1.09 to 1.41); this finding was not replicated in the Shanghai study (RR 0.97, CI 0.88 to 1.06). The screening group had more biopsies with benign results than did the control group (2 studies) (table).

\section{Conclusions}

The available evidence on breast self examination is limited. Based on 2 studies, regular breast examination does not reduce breast cancer mortality but increases the number of women who have biopsies with benign results. No studies were found on clinical breast examination.
Regular breast examination $v$ no examination in women*

\begin{tabular}{|c|c|c|c|c|c|}
\hline \multirow{2}{*}{$\begin{array}{l}\text { Outcomes at } \\
10-15 \text { years }\end{array}$} & \multirow{2}{*}{$\begin{array}{l}\text { Number } \\
\text { of studies }\end{array}$} & \multicolumn{2}{|c|}{ Weighted event rates } & \multirow[b]{2}{*}{ RRI $95 \%$ (CI) } & \multirow[b]{2}{*}{ NNH (CI) } \\
\hline & & Screening & Control & & \\
\hline $\begin{array}{c}\text { Breast cancer } \\
\text { mortality }\end{array}$ & 2 & $0.16 \%$ & $0.15 \%$ & $5 \%(-10$ to 24$)$ & Not significant \\
\hline $\begin{array}{l}\text { Biopsies with } \\
\text { benign results }\end{array}$ & 2 & $1.7 \%$ & $0.94 \%$ & $88 \%$ (77 to 99$)$ & 130 (119 to 140$)$ \\
\hline
\end{tabular}

*Abbreviations defined in glossary; weighted event rates, RRI, NNH, and $\mathrm{Cl}$ calculated from data in article.

\section{COMMENTARY}

Breast self examination appears to be finished as a means of decreasing breast cancer mortality, based on this summary by Kosters and Gøtsche of data from 2 large non-Western studies. Neither showed a hint of benefit in breast cancer mortality, despite long term follow up and a higher rate of biopsies in the women randomised to self examination instruction.

Both trials had some methodological problems. In the Shanghai study, which appears to be of higher overall quality, 519 factories were randomised to self examination instruction or to a control group. The randomisation may have been problematic since the intervention group had 10\% lower overall mortality. In the St Petersburg trial, 28 clinics were randomised to screening or to a control group. The final report of this trial has not yet been published, but the Cochrane review suggests that large numbers of women were misclassified or lost to analysis.

It is worth looking at a study not included in this summary-the UK Trial of Early Detection of Breast Cancer. ${ }^{1}$ The UK trial was not included in the Cochrane analysis because the allocation of 8 towns to screening or to a control group was not randomised. Results were presented with and without controlling for baseline differences in breast cancer mortality rates. Two towns were allocated to self examination, 2 to mammography, and 4 to comparison. Overall, allocation to self examination generated no improvement in breast cancer mortality (RR 0.99, CI 0.87 to 1.12). However, the town in which yearly self examination calendars were sent to women showed a significant decrease in breast cancer mortality (RR 0.79, CI 0.65 to 0.96).

In summary, the Shanghai study, where breast cancer incidence and mortality rates are much lower than in the West, was a high quality, but perhaps poorly randomized, trial. No evidence of benefit and some evidence of harm were shown. The comparability of the St Petersburg population to Western populations is difficult to gauge from the review. This perhaps poor quality trial also showed no benefit and some harm. A subgroup in a moderate quality trial in a Western population may have received some benefit, the magnitude of which is similar to mammography. This is scarcely definitive, but suggests that dialogue on this issue should continue.

Laura Willett, MD Robert Wood Johnson Medical School New Brunswick, New Jersey, USA

1 16-year mortality from breast cancer in the UK Trial of Early Detection of Breast Cancer. Lancet 1999;353:1909-14. 